\title{
Antibiotic Resistance of Escherichia Coli Isolated from Lake Nainital, Uttarakhand State, India
}

\author{
Neha Giri ${ }^{1}$ Anchal Lodhi ${ }^{2}$ - Devendra Singh Bisht ${ }^{1}$ - Suvarna Bhoj ${ }^{3}$ - Deepak Kumar Arya ${ }^{1 *}$ \\ ${ }^{1}$ Department of Zoology, D.S.B. Campus, Kumaun University, Nainital-263001 (Uttarakhand), India \\ ${ }^{2}$ Department of Biotechnology, S.J.C.B. Campus, Kumaun University, Bhimtal-263136 (UK), India \\ ${ }^{3}$ Government Angora Rabbit Breeding Farm, Government Veterinary Hospital Campus, Champawat-262523 \\ (Uttarakhand), India \\ *Corresponding Author Email id: dee.in@rediffmail.com
}

Received: 21.02.2021; Revised: 02.05.2021; Accepted: 29.05.2021

(C) Society for Himalayan Action Research and Development

\begin{abstract}
Researchers have encountered new challenges with the discovery of multiple drug resistance in microbes. Currently, multidrug resistant bacteria are considered a major public health concern and an emerging global epidemic. Presence of Escherichia coli in water is used as a faecal pollution measure. In this study E. coli isolates were collected from 20 sample collection sites at Lake Nainital. 20 E. coli isolates, 1 from each sample collection sites, were examined for their antibiotic response patterns against a panel of widely used 15 antibiotics. The result of this study showed $100 \%$ resistance to Penicillin G followed by Erythromycin (80\%). All isolates (100\%) were found susceptible for Gentamycin. The susceptibilities for Chloramphenicol and Co-trimoxazaole were found next to Gentamycin as 90 and $85 \%$ respectively. Multiple antibiotic resistance (MAR) index was also determined. 0.73 MAR index was observed as highest in 1 isolate. 13 out of 20 isolates had more than 0.2 MAR indices. The result reveals the origin of $E$. coli isolates from an area of high antibiotics use.
\end{abstract}

Keywords: E. coli $\bullet$ Antibiotic Resistance $\bullet$ Multi Drug Resistance $\bullet$ MAR Index

\section{Introduction}

Water-borne pathogen pollution of water bodies and related diseases is a major concern for water quality worldwide (Sahoo et al., 2012). Bacteria are well-known water contaminants, several of which can contribute to waterborne diseases. Salmonella, Camphylobacter, Staphylococcus, Clostridium, Pseudomonas and Escherichia coli are the chief human pathogens liable for water contamination and water borne diseases (Parveen et al., 1997; He et al., 2007).

In 1885 Theodor Escherich gave the first description of E. coli (Lim et al., 2010). E. coli is a Gram-negative, rod-shaped and facultative anaerobic bacterium. $E$. coli is one of the member of Enterobacteriaceae and considered as commensal of lower gasterointestinal tract of human and animal (Gordon and Cowling, 2003; Jafari et al., 2012; Ifeanyi et al., 2015).

Besides this the presence of E. coli in water bodies is generally considered as faecal contamination. Moreover, contamination of water bodies by faecal coliform bacteria carrying drug resistance genes has become an issue of water quality of national scope and significance (Panneerselvam and Arumugam, 2012). In natural environments $E$. coli is also attributed as an important vehicle for the dissemination of genes for antibiotic resistance (AR) in different 
bacteria including human pathogens (Mohanta and Goel, 2014; Bisht et al., 2019). The main factor in resistance spreading is the ability of bacteria to acquire and transmit foreign genes by moving elements such as plasmids and transposons (Li et al., 2019). Over the past two decades, there has been a significant increase in the emergence and spread of multidrug resistant bacteria (Thenmozhi et al., 2014; Bala et al., 2020).

This study investigated the presence of AR and multiple antibiotic resistance (MAR) E. coli isolates in Nainital lake water samples. We believe our findings are of tremendous significance and our findings will shed some light on this important issue for the water quality of Nainital Lake.

\section{Materials and Methods}

\section{Sampling sites and sample collection}

Lake Nainital is a natural kidney shaped lake with a high altitude, situated at an average height of $1937 \mathrm{~m}$ above sea level, $29^{\circ} 24^{\prime} \mathrm{N}$ latitude and $79^{\circ} 28^{\prime}$ E longitude (Singh and Gupta, 2014). The lake receives water from springs, rainwater and 22 inlet nullahs (Purushothaman et al., 2012). There are designated two parts of the lake at the extreme ends (northwest and southwest). There are water pump stations in each of these regions for the supply of water (through lakebank filtration technique) to the Nainital city. Within sterile 500 $\mathrm{ml}$ polypropylene bottles (Genaxy, India) water samples were obtained from 20 locations each (Table 1). Within $2 \mathrm{~h}$ of processing, the water samples were taken to the laboratory. Proper cold chain was maintained.

Table 1: Locations of sample collection sites at Nainital Lake

\begin{tabular}{|c|c|c|c|c|c|}
\hline $\begin{array}{l}\text { Sr. } \\
\text { No. }\end{array}$ & Sample & Location & Sr. No. & Sample & Location \\
\hline 1 & S1 & $\begin{array}{c}\text { Shri Maa Naina Devi } \\
\text { Temple }\end{array}$ & 11 & S11 & Library \\
\hline 2 & S2 & Pump House & 12 & S12 & Hotel Prince \\
\hline 3 & S3 & Shani Maharaj Temple & 13 & S13 & Alka Hotel \\
\hline 4 & S4 & Boat House Club & 14 & S14 & $\begin{array}{c}\text { Pasaan Devi Mata } \\
\text { Temple }\end{array}$ \\
\hline 5 & S5 & Quality Boat Stand & 15 & S15 & Hotel Elphinstone \\
\hline 6 & S6 & Shri Golu Devta Temple & 16 & S16 & Darshan Park \\
\hline 7 & S7 & New Capitol Cinema & 17 & S17 & PWD Guest House \\
\hline 8 & S8 & Hanuman Mandir & 18 & S18 & $\begin{array}{c}\text { Manu Maharani } \\
\text { Regency }\end{array}$ \\
\hline 9 & S9 & Dilli Darbar DLX & 19 & S19 & Jheel Oxygen Center \\
\hline 10 & $\mathrm{~S} 10$ & St. Francis Catholic Church & 20 & S20 & $\begin{array}{l}\text { Army Rest and } \\
\text { Recoup Centre }\end{array}$ \\
\hline
\end{tabular}

Isolation and identification of bacterial isolates

Membrane filtration and pour plate techniques were employed for analysing the water samples.
$100 \mathrm{ml}$ of water samples were filtered with sterile mixed cellulose esters (MCE) membranes (Millipore, USA) with a pore size of $0.45 \mu \mathrm{m}$ 
using a vacuum filtration system. Each MCE membrane filter was then transferred to Hi-Crome (HiMedia, India) E. coli agar (chromogenic selective agar for $E$. coli) plates. In addition, the water samples (1 ml; undiluted) were directly plated into Hi-Crome agar plates using pour plate technique. The isolates were also plated on Eosin Methylene Blue (EMB) agar culture medium (HiMedia, India) and incubated at $37^{\circ} \mathrm{C}$ for overnight. Luria-Bertani (LB) broth and agar (Difco, USA) were used for general culture of bacterial isolates. Further identification and confirmation of E. coli was done by IMViC (indole, methyl red, Voges-Proskauer and citrate utilization) test. E. coli $\mathrm{DH} 5 \alpha$ strain was used in this study as reference strain (kindly provided by Prof. A.K. Johri, School of Life Sciences, J.N.U., New Delhi, India). All the recovered isolates and reference strain were preserved in LB broth with $25 \%$ glycerol at $-80^{\circ} \mathrm{C}$ in deep freezer for future use.

\section{Antimicrobial susceptibility testing}

Susceptibility to antimicrobial agents was evaluated by the Kirby-Bauer's disk diffusion method on Muller-Hinton agar (HiMedia, India). Selection of antibiotics was based on the antibiotic prescription patterns in local hospitals and veterinary dispensaries; and the Clinical and Laboratory Standards Institute (CLSI) guidelines (earlier National Committee for Clinical Laboratory Standards guidelines) (CLSI, 2010). All the dehydrated culture media and antibiotic discs were obtained from HiMedia, India. Following 15 antibiotics were tested in this examination: Amikacin $(30 \mu \mathrm{g})$, Ampicillin (10 $\mu \mathrm{g})$, Cefixime $(5 \mu \mathrm{g})$, Cefotaxime $(5 \mu \mathrm{g})$, Cefuroxime $(30 \mu \mathrm{g})$, Chloramphenicol $(30 \mu \mathrm{g})$, Co-Trimoxazaole $(25 \mu \mathrm{g})$, Erythromycin $(15 \mu \mathrm{g})$, Gentamicin $(10 \mu \mathrm{g})$, Kanamycin $(30 \mu \mathrm{g})$, Nalidixic Acid $(30 \mu \mathrm{g})$, Norfloxacin $(10 \mu \mathrm{g})$, Penicillin G $(10 \mu \mathrm{g})$, Streptomycin $(10 \mu \mathrm{g})$ and Tetracycline $(30 \mu \mathrm{g})$. Antimicrobial sensitivity was determined by measuring the zone diameter. Zone diameters of susceptibility testing results were categorized as per CLSI guidelines (CLSI 2010). Co-resistance (resistance to 2 antibiotics) and multi-resistance (resistance to at least 3 antibiotics) were recorded. Percent resistance was determined (by dividing the number of antibiotics to which the isolate was resistant by the total number of antibiotics tested $X$ 100) for each isolate.

\section{Calculation of MAR index}

MAR indices were determined for each isolate by dividing the number of antibiotics to which the isolate was resistant by the total number of antibiotics tested (i.e., $a / b$, where $a$ is the number of antibiotics to which the isolate was resistant and $b$ is the total number of antibiotics to which the isolate was exposed; i.e., $b=15$ ) (Krumperman, 1983; Odjadjare et al., 2012).

\section{Result}

Isolation and identification of bacterial isolates Out of 20 sampling sites, 10 (S1 to S10) were located at northwest region (Mallital) and 10 (S11 to S20) at southwest region (Tallital). Typical bacterial colonies were appeared after isolation and overnight incubation on Hi-Crome E. coli agar media. Colonies with bluish green color were corresponding to E. coli. All 20 water samples were showing the presence of $E$. coli on $\mathrm{Hi}$ Crome E. coli agar media. Bacterial enumeration was not performed in this study. Distinct colonies in triplicate from each sample with morphology consistent with E. coli were picked from $\mathrm{Hi}$ Crome E. coli agar plates and inoculated onto EMB agar plates. All EMB plate showed colonies with characteristic metallic green sheen of $E$. coli (Fig. 1). From each water sample only one putative E. coli colony was picked and grown on LB broth. Thus, further study comprises 20 selected putative E. coli isolates only. These 
isolates were labelled as EC1 through EC20 respectively for their sample collection sites, i.e., S1 to S20 (Table 2). IMViC test confirmed the selected putative isolates as confirmed E. coli isolates

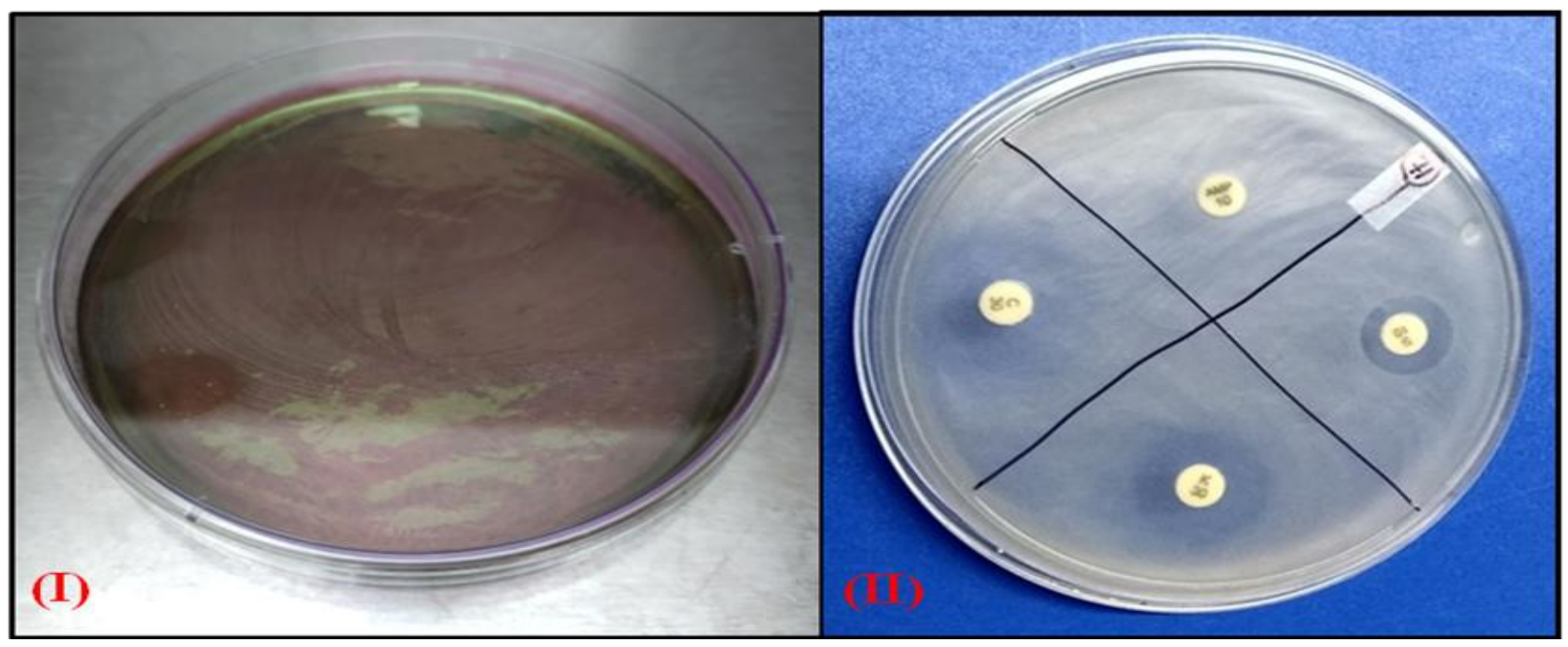

Fig. 1: E. coli isolates: (I). Sample 1 (S1/EC1) showing metallic green sheen on Eosin Methylene Blue (EMB) plate and (II). An isolate (EC8) showing resistance, susceptibility and intermediate response to antibiotics. The isolate is showing resistance against Ampicillin (AMP), susceptibility against Chloramphenicol (C); and intermediate response for Kanamycin (K) and Streptomycin (S).

\section{Antimicrobial susceptibility testing and MAR index}

E. coli isolates were categorized into 3 groups i.e. resistant $(\mathrm{R})$, intermediate (I) and susceptible (S) on the basis of zone diameter measured as per CLSI standards (Fig. 1, Table 2). Of the 20 selected E. coli isolates (EC1 to EC20) EC1 showed $73.33 \%$ resistance against tested 15 antibiotics. $60 \%$ resistance was shown by EC5 and $53.33 \%$ by EC8. 2 isolates (EC9 and EC11) showed $46.66 \%$ resistance whereas 6 isolates (EC4, EC10, EC13, EC16, EC18 and EC20) showed $40 \%$ resistance. 2 isolates (EC15 and EC17) showed $33.33 \%$ resistance and $26.66 \%$ resistance was showed by EC2 isolate. $20 \%$ resistance was shown by EC7 and EC14, while 3 isolates (EC3, EC6 and EC19) showed 13.33\% resistance. Least resistance was shown by EC12
(6.66\%) against 15 antibiotics. Among the multidrug resistance (MDR) isolates, the resistance for Penicillin $\mathrm{G}$ was observed in all the isolates $(n=20 ; 100 \%)$ followed by Erythromycin (80\%), Ampicillin (60\%), Cefotaxime (55\%); Cefuroxime (45\%); Cefixime, Norfloxacin and Tetracycline (40\% each); Amikacin, Cotrimoxazole and Nalidixic Acid (15\% each); Chloramphenicol (10\%); Kanamycin and Streptomycin (5\% each). All the isolates in this study showed resistance to one or more antibiotics except Gentamycin. Gentamycin showed 100\% susceptibility in all tested $E$. coli isolates $(\mathrm{n}=20)$ (Table 3). Least MAR index (0.06) was estimated for EC12. Further, 0.10 to 0.33 MAR indices were observed in 8 isolates. Additional 8 isolates did show indices between 0.40 and 0.46. MAR indices were 0.53 and 0.60 in $1-1$ isolates each. In this analysis we observed 1 isolate (EC1) with highest 0.73 MAR index (Table 2). 
Table 2: Antibiotic ${ }^{\Psi}$ sensitivity test $^{\varphi \omega}$ by Kirby-Bauer disk diffusion method on Muller-Hinton agar and MAR index

\begin{tabular}{|c|c|c|c|c|c|c|c|c|c|c|c|c|c|c|c|c|c|c|}
\hline $\begin{array}{l}\dot{z} \\
\dot{\dot{n}}\end{array}$ & 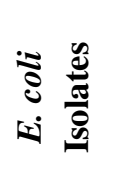 & $\frac{4}{4}$ & $\sum_{i}$ & $\sum_{\text {穵 }}$ & v & 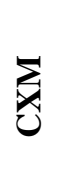 & U & రิ & 되 & 尩 & $\checkmark$ & $\overleftrightarrow{\mathbf{z}}$ & $\underline{z}$ & 2 & $\infty$ & 红 & 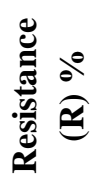 & 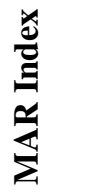 \\
\hline 1 & $\overline{\mathrm{EC} 1}$ & $\bar{R}$ & $\bar{R}$ & $\mathrm{R}$ & $\bar{R}$ & $\bar{R}$ & $\bar{R}$ & $\bar{R}$ & $\bar{R}$ & $\bar{S}$ & $\bar{R}$ & $\bar{R}$ & I & $\bar{R}$ & $\bar{S}$ & $\bar{S}$ & 73.33 & 0.73 \\
\hline 2 & $\mathrm{EC} 2$ & $S$ & $S$ & $S$ & $S$ & $S$ & $S$ & $S$ & $\mathrm{R}$ & $S$ & $S$ & $S$ & $\mathrm{R}$ & $\mathrm{R}$ & $S$ & $\mathrm{R}$ & 26.66 & 0.26 \\
\hline 3 & EC3 & S & I & S & S & I & S & S & $\mathrm{R}$ & S & S & S & S & $\mathrm{R}$ & I & I & 13.33 & 0.13 \\
\hline 4 & EC4 & $S$ & $\mathrm{R}$ & $\mathrm{R}$ & $\mathrm{R}$ & I & $S$ & S & $\mathrm{R}$ & $S$ & I & $S$ & $S$ & $\mathrm{R}$ & I & $\mathrm{R}$ & 40.00 & 0.40 \\
\hline 5 & EC5 & $\mathrm{R}$ & $\mathrm{R}$ & $\mathrm{R}$ & I & $\mathrm{R}$ & $S$ & $\mathrm{R}$ & $S$ & $S$ & $S$ & $\mathrm{R}$ & $\mathrm{R}$ & $\mathrm{R}$ & $S$ & $\mathrm{R}$ & 60.00 & 0.60 \\
\hline 6 & EC6 & I & I & S & S & S & $S$ & S & $\mathrm{R}$ & S & I & I & I & $\mathrm{R}$ & I & I & 13.33 & 0.13 \\
\hline 7 & EC7 & $S$ & $\mathrm{R}$ & I & $S$ & $S$ & $S$ & $S$ & $\mathrm{R}$ & $S$ & $S$ & $S$ & I & $\mathrm{R}$ & $S$ & $S$ & 20.00 & 0.20 \\
\hline 8 & EC8 & S & $\mathrm{R}$ & $\mathrm{R}$ & $\mathrm{R}$ & $\mathrm{R}$ & S & S & $\mathrm{R}$ & S & I & S & $\mathrm{R}$ & $\mathrm{R}$ & I & $\mathrm{R}$ & 53.33 & 0.53 \\
\hline 9 & EC9 & I & $\mathrm{R}$ & $\mathrm{R}$ & $\mathrm{R}$ & S & S & S & $\mathrm{R}$ & $S$ & I & I & $\mathrm{R}$ & $\mathrm{R}$ & $\mathrm{R}$ & S & 46.66 & 0.46 \\
\hline 10 & EC10 & $S$ & $\mathrm{R}$ & $\mathrm{R}$ & I & $\mathrm{R}$ & $S$ & S & $S$ & S & $S$ & S & $\mathrm{R}$ & $\mathrm{R}$ & I & $\mathrm{R}$ & 40.00 & 0.40 \\
\hline 11 & EC11 & $S$ & $\mathrm{R}$ & $S$ & $\mathrm{R}$ & $\mathrm{R}$ & $S$ & S & $\mathrm{R}$ & S & $S$ & S & $\mathrm{R}$ & $\mathrm{R}$ & S & $\mathrm{R}$ & 46.66 & 0.46 \\
\hline 12 & EC12 & S & S & S & S & S & S & S & S & S & S & S & I & $\mathrm{R}$ & S & S & 6.66 & 0.06 \\
\hline 13 & EC13 & I & $\mathrm{R}$ & $\mathrm{R}$ & $\mathrm{R}$ & $\mathrm{R}$ & $S$ & S & $\mathrm{R}$ & S & S & S & S & $\mathrm{R}$ & I & S & 40.00 & 0.40 \\
\hline 14 & EC14 & I & S & I & $\mathrm{R}$ & S & $S$ & S & $\mathrm{R}$ & $S$ & S & S & $S$ & $\mathrm{R}$ & S & I & 20.00 & 0.20 \\
\hline 15 & EC15 & $S$ & $\mathrm{R}$ & $S$ & $S$ & $\mathrm{R}$ & $S$ & $S$ & $\mathrm{R}$ & $S$ & $S$ & $S$ & $\mathrm{R}$ & $\mathrm{R}$ & $S$ & $S$ & 33.33 & 0.33 \\
\hline 16 & EC16 & $S$ & $\mathrm{R}$ & $S$ & $\mathrm{R}$ & $\mathrm{R}$ & S & $S$ & $\mathrm{R}$ & $S$ & $S$ & $S$ & $S$ & $\mathrm{R}$ & $S$ & $\mathrm{R}$ & 40.00 & 0.40 \\
\hline 17 & EC17 & I & S & S & $\mathrm{R}$ & $S$ & $\mathrm{R}$ & S & $\mathrm{R}$ & S & S & S & $S$ & $\mathrm{R}$ & $S$ & $\mathrm{R}$ & 33.33 & 0.33 \\
\hline 18 & EC18 & $S$ & $S$ & $S$ & $\mathrm{R}$ & $\mathrm{R}$ & $S$ & $\mathrm{R}$ & $\mathrm{R}$ & $S$ & I & I & $\mathrm{R}$ & $\mathrm{R}$ & I & I & 40.00 & 0.40 \\
\hline 19 & EC19 & $S$ & S & $S$ & $\mathrm{R}$ & I & $S$ & S & $S$ & S & S & S & I & $\mathrm{R}$ & S & $S$ & 13.33 & 0.13 \\
\hline 20 & EC20 & $\mathrm{R}$ & $\mathrm{R}$ & $\mathrm{R}$ & I & S & $S$ & S & $\mathrm{R}$ & $S$ & S & $\mathrm{R}$ & I & $\mathrm{R}$ & S & I & 40.00 & 0.40 \\
\hline
\end{tabular}

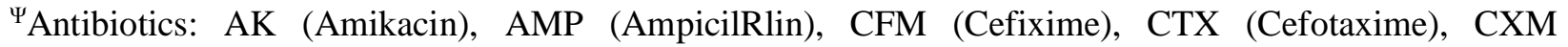
(Cefuroxime), C (Chloramphenicol), CoT (Co-Trimoxazaole), E (Erythromycin), GEN (Gentamicin), K (Kanamycine), NA (Nalidixic Acid), NX (Norfloxacin), P (Penicillin G), S (Streptomycin) and TE (Tetracycline). ${ }^{\omega} \mathrm{R}=\mathrm{Resistant}, \mathrm{I}=$ Intermediate and $\mathrm{S}=$ Susceptible ${ }^{\varphi} E$. coli $\mathrm{DH} 5 \alpha$ showed resistance to Nalidixic Acid only

\section{Discussion}

Nainital Lake is subtropical water body located in the Kumaun region of Uttarakhand. It serves to supply drinking water to the city and also is a big tourist attraction. The lake plays important role in socio-economic development of hill people. There has been a rapid deterioration in the water quality of the lake due to intense activities in the catchment area of the lake. The city has an over 60 year old sewage system which often chokes and bursts. The sewage overflows into rainwater channels which lead to the lake (Dash et al., 2008). This study was conducted to check the water quality and potential health risk assessment 
of the Nainital Lake. Prevalence of E. coli in all lake water samples confirmed widespread faecal contamination in the waterbed. Unacceptable levels of coliform bacteria has already reported in the Nainital Lake and other water resources of the region (Dash et al., 2008; Jain et al., 2010; Rawat et al., 2012; Tyagi et al., 2015, Bisht et al., 2019). Most of the E. coli strains are harmless; some strains are pathogenic and cause death-causing diseases such as watery diarrhoea, bloody diarrhoea, urinary tract inflammation, meningitis and sepsis (Cho et al., 2018). Even though antibiotic sensitivity test was conducted on relatively less numbers of bacterial isolates, we got all isolates resistant to at least one of the tested antibiotics. The results showed high-level resistance against Penicillin G (100\%) and Erythromycin $(80 \%)$ whereas high level of susceptibility was recorded for Gentamicin (100\%) followed by Chloramphenicol (90\%) and Co-trimoxazole $(85 \%)$. We already have found high Penicillin $\mathrm{G}$ resistance of E. coli isolates (recovered from drinking water sources) in our previous work (Bisht et al., 2019). It is may be due to inadequate and ineffective antimicrobial administration of antimicrobial agents in the area. Widespread AR in the environment is now at alarming situation for India and it has been reported every now and then (Walsh et al., 2011; Akiba et al., 2015; Gandra et al., 2016; DBT, 2017; Taneja and Sharma, 2019). Like ours, other studies also revealed hilly areas that have remained isolated for a long time are now reported to have potential AR threat (Rather et al., 2013; Ahammad et al., 2014; Poonia et al., 2014; DBT, 2017; Singh et al., 2020).

Table 3: Antibacterial resistance pattern of the $E$. coli isolates $(n=20)$

\begin{tabular}{cccccccc}
\hline Sr. & Antibiotics & \multicolumn{2}{c}{ Resistance isolates } & \multicolumn{2}{c}{ Intermediate isolates } & \multicolumn{2}{c}{ Susceptible isolates } \\
\cline { 3 - 7 } & & Numbers & Percentages & Numbers & Percentages & Numbers & Percentages \\
\cline { 3 - 7 } & & 3 & 15 & 5 & 25 & 12 & 60 \\
$\mathbf{1}$ & Amikacin & 12 & 60 & 2 & 10 & 6 & 30 \\
$\mathbf{2}$ & Ampicillin & 8 & 40 & 2 & 10 & 10 & 50 \\
$\mathbf{3}$ & Cefixime & 11 & 55 & 3 & 15 & 6 & 30 \\
$\mathbf{4}$ & Cefotaxime & 9 & 45 & 3 & 15 & 8 & 40 \\
$\mathbf{5}$ & Cefuroxime & 10 & 0 & 0 & 18 & 90 \\
$\mathbf{6}$ & Chloramphenicol & 2 & 15 & 0 & 0 & 17 & 85 \\
$\mathbf{7}$ & Co-trimoxazaole & 3 & 80 & 0 & 0 & 4 & 20 \\
$\mathbf{8}$ & Erythromycin & 16 & 0 & 0 & 0 & 20 & 100 \\
$\mathbf{9}$ & Gentamycin & 0 & 5 & 5 & 25 & 14 & 70 \\
$\mathbf{1 0}$ & Kanamycin & 1 & 15 & 3 & 15 & 14 & 70 \\
$\mathbf{1 1}$ & Nalidixic Acid & 3 & 40 & 6 & 30 & 6 & 30 \\
$\mathbf{1 2}$ & Norfloxacin & 8 & 100 & 0 & 0 & 0 & 0 \\
$\mathbf{1 3}$ & Penicillin G & 20 & 5 & 7 & 35 & 12 & 60 \\
$\mathbf{1 4}$ & Streptomycin & 1 & 40 & 5 & 25 & 7 & 35 \\
$\mathbf{1 5}$ & Tetracycline & 8 & & & &
\end{tabular}

MAR index or profile provides useful information regarding the overall health risk assessment. The
0.2 MAR indicate source bacteria with less antibiotic usage, MAR index $>0.2$ indicates high- 
risk contamination sources while values 0.4 or higher MAR index is associated with human faecal contamination source (Kaneene et al., 2007; Kathleen et al., 2007; Mishra et al., 2013). High MAR indices need close monitoring and remedial action. In this analysis 13 out of 20 isolates had MAR index $>0.2$. A high MAR index for all samples suggests that these antibiotics have been used highly indiscriminately in the area. High MAR indices mandate vigilant surveillance and remedial measures. The Nainital Lake is a receptacle of water and waste water from adjoining areas and the catchments. Drains that enter the lake are one of the sources of pollution and contamination. The Nainital Lake has two basins Mallital and Tallital. Mallital (northwest basin) is a highly polluted site due to high population and intense tourist activities at this area. Also a major drain, Naina Devi Mandir drain, emptying into this area of lake. Tallital (southwest basin) on the other hand is relatively less polluted may be because of comparatively less human population and minor drains.

In developing countries such as India, AR has become a major problem, and the existence of resistant organisms in aquatic environment is a growing concern around the world. This is due to several reasons, including over-use and overexposure of medicinal products, easy availability of antibiotics even without medical prescription, incomplete antibiotic treatments, poor hygiene, poor management of human waste and low literacy that cause poor water quality directly or indirectly (Watkinson et al., 2007; Ishii and Sadowsky, 2008). In the water bodies the AR character can easily passes from avirulent or less virulent bacteria to the other highly virulent bacteria and their virulent strains like diarrheagenic $E$. coli, Clostridium, Campylobacter, Vibrio, Shigella, Salmonella, Pseudomonas, Legionella through horizontal gene transfer. The expected transfer of AR might add to the burden of bacterial infectious diseases.
Therefore, the issue of AR can be addressed by conducting antibiotic surveillance studies, raising public awareness and concerted efforts among physicians, research scientists, students, researchers, pharmaceutical industry and policy makers, involving government and nongovernmental organizations. Moreover, this problem should be brought to the attention of all members of society so that we can maintain the effectiveness of antibiotics currently available.

\section{Acknowledgment}

This study was supported by University Grant Commission (UGC) India, through UGC-BSR Research Start-Up-Grant to DKA. The funding from UGC is highly acknowledged. We thank to Prof. AK Johri (School of Life Sciences, JNU, New Delhi) for kindly providing E. coli $\mathrm{DH} 5 \alpha$ strain and other scientific support. We would also like to thank the Heads, Department of Zoology, DSB Campus, Nainital and Department of Biotechnology, SJCB Campus, Bhimtal for procuring necessary facilities for the present research work.

\section{References}

Ahammad ZS, Sreekrishnan TR, Hands CL, Knapp CW and Graham DW (2014) Increased water borne bla $a_{\mathrm{NDM}-1}$ resistance gene abundances associated with seasonal human pilgrimages to the upper Ganges River. Environ. Sci. Technol. 48: 3014-3020.

Akiba M, Senba H, Otagiri H, Prabhasankar VP, Taniyasu S, Yamashita N, Lee K, Yamamoto $\mathrm{T}$, Tsutsui T, Ian Joshua D, Balakrishna K, Bairy I, Iwata T, Kusumoto M, Kannan K and Guruge KS (2015) Impact of wastewater from different sources on the prevalence of antimicrobial-resistant Escherichia coli in 
sewage treatment plants in South India. Ecotoxicol. Environ. Saf. 115: 203-208.

Bala R, Singh VA, Gupta N and Rakshit P (2020) Prevalence, multidrug-resistance and risk factors for AmpC $\beta$-lactamases producing Escherichia coli from hospitalized patients. J. Infect. Dev. Ctries. 14: 1466-1469.

Bisht DS, Giri N, Lodhi A and Arya DK (2019) Coliform contamination as an indicator for potability of different drinking water sources in and around the Nainital City, Western Himalaya, Uttarakhand. Adv. Biores. 10:6065.

Cho S, Hiott LM, Barrett JB, McMillan EA, House SL, Humayoun SB, Adams ES, Jackson CR and Frye JG (2018) Prevalence and characterization of Escherichia coli isolated from the Upper Oconee Watershed in Northeast Georgia. PLoS ONE. 13: 1-15.

Clinical and Laboratory Standards Institute (2010) Twentieth informational supplement (document M100-S20); The CLSI: Wayne, PA, USA. 2010.

Dash RR, Mehrotra I, Kumar P and Grischek (2008) Lake bank filtration at Nainital, India: water-quality evaluation. Hydrogeol. J. 16: 1089-1099.

DBT (2017) Scoping report on antimicrobial resistance in India. Department of Biotechnology; New Delhi, India.

Gandra S, Mojica N, Klein EY, Ashok A, Nerurkar V, Kumari M, Ramesh U, Dey S, Vadwai V, Das BR and Laxminarayan $R$ (2016) Trends in antibiotic resistance among major bacterial pathogens isolated from blood cultures tested at a large private laboratory network in India, 2008-2014. Int. J. Infect. Dis. 50: 75-82.

Gordon DM and Cowling A (2003) The distribution and genetic structure of Escherichia coli in Australian vertebrates: Host and geographic effects. Microbiol. 149: 3575-3586.
He LM, Lu J and Shi W (2007) Variability of faecal indicator bacteria in flowing and ponded waters in southern California: implications for bacterial TMDL development and implementation. Water Res.41: 3132-3140.

Ifeanyi CIC, Ikeneche NF, Bassey BE, Al-Gallas N, Aissa RB and Boudabous A (2015) Diarrheagenic Escherichia coli pathotypes isolated from children with diarrhea in the Federal Capital Territory Abuja, Nigeria. J. Infect. Dev. Ctries. 9: 165-174.

Ishii S and Sadowsky MJ (2008) Escherichia coli in the environment: Implications for water quality and human health. Microbes Environ. 23: 101-108.

Jafari A, Aslani M and Bouzari S (2012) Escherichia coli: A brief review of diarrheagenic pathotypes and their role in diarrheal diseases in Iran. Iran. J. Microbiol. 4: 102-117.

Jain CK, Bandyopadhyay A and Bhadra A (2010) Assessment of ground water quality for drinking purpose, District Nainital, Uttarakhand, India. Environ. Monit. Assess. 166: 663-676.

Kaneene BJ, Miller R, Sayah R, Johnson YJ, Gilliland D and Gardiner JC (2007) Considerations when using discriminant function analysis of antimicrobial resistance profiles to identify sources of faecal contamination of surface water in Michigan. Appl. Environ. Microbiol. 73: 2878-2890.

Kathleen MM, Samuel L, Felecia C, Reagan L, Kasing A, Lesley M and Toh SC (2016) Antibiotic resistance of diverse bacteria from aquaculture in Borneo. Int. J. Microbiol. 16: $1-9$.

Krumperman PH (1983) Multiple antibiotic resistance indexing of Escherichia coli to identify high-risk sources of faecal contamination of foods. Appl. Environ. Microbiol. 46: 165-170. 
Li Q, Chang W, Zhang H, Hu D and Wang X (2019) The role of plasmids in the multiple antibiotic resistance transfer in ESBLsProducing Escherichia coli isolated from wastewater treatment plants. Front. Microbiol.10: 1-10.

Lim JY, Yoon JW and Hovde CJ (2010) A brief overview of Escherichia coli $\mathrm{O} 157: \mathrm{H} 7$ and its plasmid O157. J. Microbiol. Biotechnol. 20: 5-14.

Mishra M, Patel AK and Behera N (2013) Prevalence of multidrug resistant E. coli in the river Mahanadi of Sambalpur. Curr. Res. Microbiol. Biotechnol. 1: 239-244.

Mohanta T and Goel S (2014) Prevalence of antibiotic-resistant bacteria in three different aquatic environments over three seasons. Environ. Monit. Assesss. 186: 5089-5100.

Odjadjare EE, Igbinosa EO, Mordi R, Igere B, Igeleke CL and Okoh AI (2012) Prevalence of Multiple Antibiotics Resistant (MAR) Pseudomonas species in the final effluents of three municipal wastewater treatment facilities in South Africa. Int. J. Environ. Res. Pub. Health. 9: 2092-2107.

Panneerselvam A and Arumugam G (2012) Isolation and identification of bacteria from lake water in and around Ranipet Area, Vellore District. Int. J. Pharm. Biol. Arch. 3: 1008-1011.

Parveen S, Murphree RL, Edmiston L, Kaspar CW, Portier KM and Tamplin ML (1997) Association of multiple-antibiotic-resistance profiles with point and nonpoint sources of Escherichia coli in Apalachicola Bay. Appl. Environ. Microbiol. 63: 2607-2612.

Poonia S, Singh TS and Tsering DC (2014) Antibiotic susceptibility profile of bacteria isolated from natural sources of water from rural areas of East Sikkim. Ind. J. Community Med. 39: 156-160.

Purushothaman P, Mishra S, Das A and Chakrapani GJ (2012) Sediment and hydro biogeochemistry of Lake Nainital, Kumaun Himalaya, India. Environ. Earth Sci. 65: 775788.

Rather TA, Hussain SA, Bhat SA, Shah SN, Arshid S and Shahnawaz M (2013) Antibiotic sensitivity of $E$. coli and Salmonella isolated from different water sources in Kashmir, India. Comp. Clin. Pathol. 22: 729-731.

Rawat V, Jha SK, Bag A, Singhai M and Rawat CM (2012) The bacteriological quality of drinking water in Haldwani block of Nainital district, Uttarakhand India. J. Water Health. 10: 465-470.

Sahoo KC, TamhankarAJ, Sahoo S, Sahu PS, Klintz SR and Lundborg CS (2012) Geographical variation in antibiotic-resistant Escherichia coli isolates from stool, cow dungs and drinking water. Int. J. Environ. Res. 9: 746-759.

Singh AK, Das S, Kumar S, Gajamer VR, Najar IN, Lepcha YD, Tiwari HK and Singh S (2020) Distribution of antibioticresistant Enterobacteriaceae pathogens in potable spring water of Eastern Indian Himalayas: emphasis on virulence gene and antibiotic resistance genes in Escherichia coli. Front. Microbiol. 11: 581072.

Singh N and Gupta PK (2014) Reproductive biology of eastern mosquito fish Gambusia holbrooki (Girard) (Poeciliiadae) in a subtropical Lake, Lake Nainital (India). Int. J. Curr. Microbiol. Appl. Sci.3: 19-31.

Taneja N and Sharma M (2019) Antimicrobial resistance in the environment: The Indian scenario. Ind. J.Med. Res. 149: 119-128.

Thenmozhi S, Rajeswari P, Suresh Kumar T, Saipriyanga V and Kalpana M (2014) Multidrug resistant patterns of biofilm forming Aeromonas hydrophila from urine samples. Int. J. Pharm. Sci. Res. 5: 2908-2918.

Tyagi S, Singh P, Sharma B, Sing R, Dobhal R and Uniyal DP (2015) Bacteriological 
J. Mountain Res. P-ISSN: 0974-3030, E-ISSN: 2582-5011

Vol. 16(1), (2021), 127-136

DOI: https://doi.org/10.51220/jmr.v16il.12

assessment of drinking water sources of Uttarakhand, India. Natl. Acad. Sci. Lett. 38: $37-44$.

Walsh TR, Weeks J, Livermore DM and Toleman MA (2011) Dissemination of NDM-1 positive bacteria in the New Delhi environment and its implications for human health: An environmental point prevalence study. Lancet Infect. Dis. 11: 355-362.

Watkinson AJ, Micalizzi GB, Graham GM, Bates JB and Costanzo SD (2007) Antibioticresistant Escherichia coli in wastewaters, surface waters and oysters from an urban riverine system. Appl. Environ. Microbiol. 73: 5667-5670.

$* * * * * * *$ 